\title{
Multi-scale characterization of ceramic inert-substrate- supported and co-sintered solid oxide fuel cells
}

\author{
Florian Wankmüller ${ }^{1, *}$ (D), Matthias Meffert ${ }^{2}$, Niklas Russner ${ }^{1}$, André Weber ${ }^{1}$, Johannes Schmieg ${ }^{1,2}$, \\ Heike Störmer ${ }^{2}$, Thorsten Dickel ${ }^{3}$, Piero Lupetin ${ }^{4}$, Nicolas Maier ${ }^{4}$, Dagmar Gerthsen ${ }^{2}$, and \\ Ellen Ivers-Tiffée ${ }^{1}$ \\ ${ }^{1}$ Institute for Applied Materials (IAM-WET), Karlsruhe Institute of Technology (KIT), Adenauerring 20b, 76131 Karlsruhe, Germany \\ ${ }^{2}$ Laboratory for Electron Microscopy (LEM), Karlsruhe Institute of Technology (KIT), Engesserstraße 7, 76131 Karlsruhe, Germany \\ ${ }^{3}$ RJL Micro \& Analytic, Im Entenfang 11, 76689 Karlsdorf-Neuthard, Germany \\ ${ }^{4}$ Robert Bosch GmbH, Robert-Bosch-Campus 1, 71272 Renningen, Germany
}

Received: 28 April 2020

Accepted: 22 May 2020

Published online:

3 June 2020

(C) The Author(s) 2020

\begin{abstract}
Understanding cell performance is essential for selecting cell components and the processing parameters for solid oxide fuel cells. The scale of relevant microstructural features in electrodes, electrolyte and supporting substrate covers several orders of magnitude. This contribution will demonstrate how advanced correlative multi-scale tomography can be used to identify those parameters: ranging from millimeter to nanometer scale. We employ optical microscopy, X-ray computed tomography $(\mu-\mathrm{CT})$, focused ion beam-scanning electron microscopy tomography and energy-dispersive X-ray spectroscopyscanning transmission electron microscopy. Additional investigations by selected area electron diffraction allow a determination of the underlying crystal structures. An SOFC design based on the co-sintering of an inert substrate with various functional layers on top is used as a blueprint, allowing further methodological development. The effect of interdiffusion between phases and development of secondary phases on microstructure and chemical composition will be shown. Furthermore, porosity and tortuosity extracted individually from all porous layers will allow modeling of gas diffusion loss contributions within the co-fired cell structure. This exemplifies how correlative tomography helps to understand specific contributions to overall cell performance.
\end{abstract}

Abbreviations

ASR Area specific resistance

CCL Cathode current collector layer (LSM)
CFL Cathode functional layer (LSM-YSZ)

CT X-ray computed tomography

$\mathrm{D}_{\mathrm{K}, \mathrm{O} 2}$ Oxygen Knudsen diffusion coefficient

Address correspondence to E-mail: florian.wankmueller@kit.edu 


\begin{tabular}{|c|c|}
\hline $\mathrm{D}_{\mathrm{N} 2, \mathrm{O} 2}$ & $\begin{array}{l}\text { Binary gas diffusion coefficient of oxygen } \\
\text { and nitrogen }\end{array}$ \\
\hline$\varepsilon$ & Material fraction \\
\hline EDXS & Energy-dispersive X-ray spectroscopy \\
\hline ETD & Everhart-Thornley detector \\
\hline FIB & Focused ion beam \\
\hline ICD & In-column detector \\
\hline LSM & $\left(\mathrm{La}_{0.8} \mathrm{Sr}_{0.2}\right)_{0.98} \mathrm{MnO}_{3-\delta}$ \\
\hline $1_{\mathrm{TPB}}$ & Triple-phase boundary length \\
\hline MD & Mirror detector \\
\hline $\mathrm{OM}$ & Optical microscopy \\
\hline $\mathrm{pO}_{2}$ & Oxygen partial pressure \\
\hline SEM & Scanning electron microscopy \\
\hline SOFC & Solid oxide fuel cell \\
\hline STEM & Scanning transmission electron microsco \\
\hline $\mathrm{T}$ & Temperature \\
\hline$\tau$ & Tortuosity factor \\
\hline TLD & Through-the-lens detector \\
\hline YSZ & $8 \mathrm{~mol} \% \mathrm{Y}_{2} \mathrm{O}_{3}$-doped $\mathrm{ZrO}_{2}$ \\
\hline
\end{tabular}

\section{Introduction}

Solid oxide fuel cells (SOFCs) are a technology with huge potential due to their high combined heat and power efficiency and low emissions [1]. Among them, the best established and well-proven are anode-supported (ASC) [2-5] and electrolyte-supported (ESC) $[6,7]$ cell designs. In ASC, the nickel/stabilized zirconia anodes of $250 \mu \mathrm{m}$ up to $1500 \mu \mathrm{m}$ thickness act as mechanical support, and the $10-\mu \mathrm{m}$ - to $1-\mu \mathrm{m}$-thin electrolytes allow moderate ohmic loss contributions even at low to medium operation temperatures (600-800 $\left.{ }^{\circ} \mathrm{C}\right)$. In ESC, yttria-, ytterbia- or scandiadoped zirconia ( $80 \mu \mathrm{m}$ to $150 \mu \mathrm{m}$ thickness) provides mechanical strength, and both electrodes are $<50 \mu \mathrm{m}$ thick. This configuration necessitates medium to high operation temperatures $\left(750-900{ }^{\circ} \mathrm{C}\right)$, but has advantages in manufacture and is highly robust during anodic re-oxidation cycles. Also, there are other designs such as inert-substrate-supported SOFCs [8-10] where ceramics, e.g., porous zirconia, have been applied as electrochemically inactive (inert) supporting structure. Besides this, oxide-based and metallic substrate-supported SOFCs are under development [11-16]. All of them represent interesting alternatives to ASC and ESC, mainly because they replace large volumes of expensive zirconia-based raw materials with less expensive ones.

Another inert silicate-supported SOFC was initially introduced in [17] where the functional and support layers are co-sintered in a single step at temperatures between 1100 and $1300{ }^{\circ} \mathrm{C}$. This inert support provides large pore volumes and pore diameters for gas supply to the cathode. The electric current flows inplane through the cathode current collector layer (CCL), whereas the oxygen reduction reaction is confined to the cathode functional layer (CFL), made of $\left(\mathrm{La}_{0.8}, \mathrm{Sr}_{0.2}\right)_{0.98} \mathrm{MnO}_{3-\delta}$ (LSM) and $8 \mathrm{~mol} \% \mathrm{Y}_{2} \mathrm{O}_{3^{-}}$ doped $\mathrm{ZrO}_{2}$ (8YSZ). Hydrogen oxidation takes place within a standard-type, nickel/8YSZ cermet anode (cf. section "SOFC fabrication and operation").

It is well known from the literature that the formation of secondary phases can drastically hamper the efficiency of electrochemically active interfaces [18-22]. It may become even more complicated, when an inert support layer is involved. During co-sintering, in particular, there are further challenges that have to be addressed:

- Co-sintering is always a compromise in terms of sintering temperature: (i) the sintering temperature must be high enough to ensure the gas tightness of the electrolyte. (ii) On the cathode side, however, possible formation of foreign phases such as $\mathrm{SrZrO}_{3}$ and $\mathrm{La}_{2} \mathrm{Zr}_{2} \mathrm{O}_{7}$ must be considered. Although sub-stoichiometry on the A-site of the LSM-perovskite suppresses the formation of foreign phases [23], the present sintering temperature between 1100 and $1300{ }^{\circ} \mathrm{C}$ is in the range where foreign phases can occur [24].

- The limitations of sintering temperature due cosintering requirements limit the possibility of tuning electrodes microstructures in order to enhance the electrochemical efficiency.

- The selected A-site sub-stoichiometry of the LSM increases the diffusion probability of manganese cations of the B-site. This can have an effect on various cell areas that need to be investigated. Kawada et al., for example, showed the relation of manganese doping of 8YSZ to conductivity [25]. 2 mol.\% manganese in 8YSZ would be, in terms of conductivity, equivalent to a content of $9.8 \mathrm{~mol} . \%$ $\mathrm{Y}_{2} \mathrm{O}_{3}$ in $\mathrm{ZrO}_{2}$. This would correspond to a reduction in conductivity of about $20 \%$ compared to $8 Y S Z$. 
- The thermal expansion coefficient and sintering properties of all layers must be considered to prevent crack formation or bending. Adaption of sintering process (heating rate, holding time, temperature steps) is necessary.

- The potential of glass phase formation [26-28] caused by volatile silicon originating from the support and associated performance losses must be investigated.

The effect of co-sintering on the microstructure of such a complex multilayer structure has to be studied from the macroscopic to the nanometer scale. In this study, we address the abovementioned challenges and particularly aim at analyzing:

- The influence of inert porous support characteristics on cathode gas supply

- The consequence of co-firing on chemical composition, volume and local precipitation of secondary phases (formed via solid/solid reactions or via gas transport)

- The effect of co-firing on interdiffusion among and microstructure changes in functional layers (cathode functional layer, electrolyte, anode)

The analytical methods applied are (i) optical microscopy (OM), (ii) X-ray computed tomography ( $\mu$-CT), (iii) scanning electron microscopy (SEM), (iv) SEM serial sectioning tomography using a focused ion beam (FIB) and (v) scanning transmission electron microscopy (STEM) combined with energy-dispersive X-ray spectroscopy (EDXS). With our findings, we give examples of how correlative tomography and elemental analyses help to link fabrication parameters with chemical and microstructural features and to understand specific contributions to overall cell performance.

\section{Experimental}

\section{SOFC fabrication and operation}

The investigated cell sample (cf. Fig. 1 or [17, 29-32]) consists of (i) a porous silicate support (layer thickness $1250 \mu \mathrm{m}$ ) composed of $\mathrm{Zn}, \mathrm{Mg}$ and $\mathrm{Si}$, (ii) a cathode current collector layer (CCL, layer thickness after sintering $70 \mu \mathrm{m})$ composed of $\left(\mathrm{La}_{0.8} \mathrm{Sr}_{0.2}\right)_{0.98} \mathrm{MnO}_{3-\delta}$ (LSM), (iii) a cathode functional layer (CFL, layer thickness $16 \mu \mathrm{m}$ ) composed of
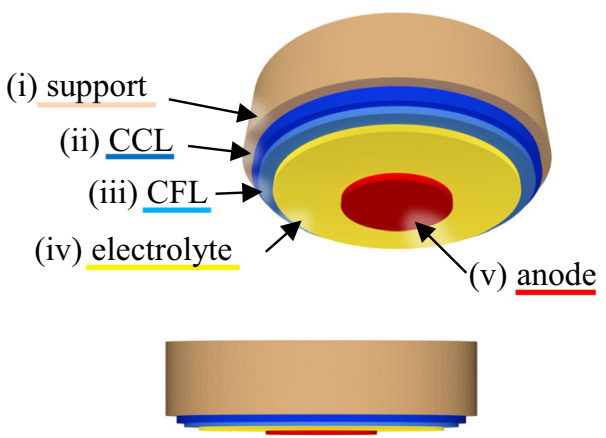

Figure 1 Schematic cell layout: (i) porous silicate support composed of $\mathrm{Zn}, \mathrm{Mg}$ and $\mathrm{Si}$; (ii) LSM CCL; (iii) LSM/8YSZ composite as CFL; (iv) 8 YSZ electrolyte and (v) Ni/8YSZ cermet anode.

$\mathrm{LSM} / 8$ mol. $\% \mathrm{Y}_{2} \mathrm{O}_{3}$-doped $\mathrm{ZrO}_{2}$ (LSM/8YSZ, ratio 50:50 wt.\%), (iv) a dense electrolyte (8YSZ, layer thickness $15 \mu \mathrm{m}$ ) and (v) a Ni/8YSZ anode (layer thickness $15 \mu \mathrm{m})$. All functional layers were fabricated by screen printing and then laminated onto the substrate. The whole cell was co-fired at a temperature between $1100{ }^{\circ} \mathrm{C}$ and $1300{ }^{\circ} \mathrm{C}$.

Due to the challenges associated with co-sintering, the composition of the screen printed inks was selected and adapted in order to tune the sintering behavior of all layers and to obtain a crack-free cell after sintering. In this context, characteristics of raw powders, paste composition and paste processing were chosen and adapted.

To avoid anode delamination, sintering and mechanical properties were adjusted by adapting raw material powders, pore forming agents as well as paste composition and paste processing.

In addition, A-site sub-stoichiometric LSM was chosen in order to avoid the formation of lanthanum zirconate during the thermal process. The implementation of alternative cathode materials was also investigated in a separate study [33,34].

For testing, the cell was heated to $900{ }^{\circ} \mathrm{C}$ (sealing step), followed by a 4 -h reduction procedure at $850^{\circ} \mathrm{C}$. The investigated sample was then operated for a few hours in a test bench at $T=750{ }^{\circ} \mathrm{C}$ with air supply at the cathode side ( $2 \mathrm{NL} \mathrm{min}^{-1}$ synthetic air) and hydrogen supply at the anode side $\left(0.7 \mathrm{NL} \mathrm{min}^{-1}\right)$ - with a fuel utilization of less than $5 \%$. Cell functionality was recently tested over $1200 \mathrm{~h}$ operation time [29] with a constant current load of $150 \mathrm{~mA} \mathrm{~cm}^{-2}$. The load was interrupted every $100 \mathrm{~h}$ for impedance measurements $(1 \mathrm{MHz}$ to $30 \mathrm{mHz}$ with a voltage excitation signal of $50 \mathrm{mV}$ and no 
bias). A 2000-h functionality test was also successfully performed (not published yet).

\section{Preparation for further investigation}

After anode reduction and operation for a few hours at $T=750{ }^{\circ} \mathrm{C}$, the investigated cell is cooled to room temperature under reducing conditions. Then, the entire cell is broken into pieces. One of those, subsequently referred to as Sample 1A, was used without any further treatment for OM and SEM analysis for qualitatively investigating cell functional layers and support. Another piece of the same cell as Sample 1A, referred to as Sample 1B, was vacuum-infiltrated with a two-component epoxy resin (EpoFix, Struers $\mathrm{GmbH}$, Willich, Germany) to provide better mechanical stability and enhance material contrast between the phases [20,35]. For this purpose, a piece of the sample was placed in the vacuum chamber. After evacuation, the resin is injected into the chamber in a dropwise manner. This slowly encloses and covers the sample. After waiting a few minutes until remaining bubbles have escaped from the sampleresin structure, the chamber is flooded. After hardening, isolated, smaller volumes of the infiltrated sample (Sample 1B) were then prepared for further investigation with $\mu-C T, F I B / S E M$ and STEM.

\section{Optical microscopy}

A Keyence VHX-6000 digital microscope (Keyence Deutschland $\mathrm{GmbH}$, Neu-Isenburg, Germany) is used for optical microscopy (light source: LED, $5700 \mathrm{~K})$. The microscope is equipped with an objective lens (VH-Z500) that allows magnifications between $500 \times$ and $5000 \times$. Virtual stitching of adjacent areas yields large fields-of-view at high resolution. A high depth of focus is achieved by a focus stacking algorithm implemented in the Keyence software.

\section{$\mu-\mathrm{CT}$}

A Bruker SkyScan 2211 system (Bruker Corporation, Billerica, USA) was used. This $\mu$-CT system is equipped with an X-RAY WorX TCNF X-Ray source (X-RAY WorX GmbH, Garbsen, Germany) with a minimum spot size of $0.5 \mu \mathrm{m}$ and a maximum acceleration voltage of $190 \mathrm{kV}$. The system has two X-ray detectors, the Varex CMOS 1512 detector
(Varex Imaging Corporation, Salt Lake City, USA) with a high sensitivity and a resolution of up to $0.4 \mu \mathrm{m} /$ voxel and a Ximea OnSemi KAI-11002 CCD detector (XIMEA GmbH, Muenster, Germany) for high-resolution images of up to $0.2 \mu \mathrm{m} /$ voxel. The substrate scans were performed with the CMOS detector, which provides a better signal-to-noise ratio to achieve a clear segmentation of the material structure. The total scan time was $4.5 \mathrm{~h}$, performing 3601 projections at a resolution of $0.5 \mu \mathrm{m} /$ voxel (source voltage $60 \mathrm{kV}$, source current $500 \mu \mathrm{A}$ ). The functional layers were investigated with the CCD detector to achieve optimum structure resolution (voxel size $0.2 \mu \mathrm{m}$ ). A longer exposure time was chosen to perform 1294 projections, resulting in a total scan time of $9 \mathrm{~h}$ (source voltage $80 \mathrm{kV}$, source current $250 \mu \mathrm{A}$ ). Due to the high density of the functional layers, the camera is equipped with a 0.25 $\mathrm{mm}$ aluminum filter to achieve a better contrast ratio.

\section{SEM imaging and FIB-SEM tomography}

Sequential SEM imaging and FIB milling (FIB/SEM tomography) provides spatial information with a higher resolution compared to $\mu$-CT. Small features with sizes in the order of $10 \mathrm{~nm}$ can be reliably detected [36]. Material contrast is improved using epoxy resin to fill the pores. Datasets for FIB/SEM tomography were obtained with a Thermo Scientific $^{\mathrm{TM}}$ Helios G4 FX DualBeam ${ }^{\mathrm{TM}}$ (Thermo Fisher Scientific, Waltham, Massachusetts, USA) microscope. Material contrast for anode materials (Ni and YSZ) was obtained by secondary-electron imaging with a though-the-lens detector (TLD) using $3 \mathrm{keV}$ electrons and a beam current of $0.8 \mathrm{nA}$. Backscattered-electron imaging using the in-column backscattered-electron detectors (mirror detector (MD) and in-column detector (ICD)) yielded material contrast for cathode and electrolyte materials. Imaging was performed at electron energies between 3 and $5 \mathrm{keV}$ and beam currents between 0.8 and $6.4 \mathrm{nA}$. Details on FIB/SEM processing are given by Joos et al. [20, 35]. Information on image filtering, segmentation and parameter determination can be found in [20, 35, 37].

A ZEISS 1540XB CrossBeam workstation (Carl Zeiss NTS GmbH, Oberkochen, Germany) was used for standard SEM microstructure investigations of cross-sectional surfaces as well as for FIB/SEM tomography of the substrate/cathode interface using 
the Everhart-Thornley (ETD) and Inlens detectors. Material contrast was obtained by secondary-electron imaging with the Inlens detector, using an electron energy of $1.3 \mathrm{keV}$ and a beam current of $0.15 \mathrm{nA}$.

\section{STEM-EDXS}

The elemental distributions and chemical compositions of the functional layers and of the cathode/support interface were determined by EDXS in a FEI (now: Thermo Fisher Scientific) Tecnai Osiris ChemiSTEM transmission electron microscope operated at $200 \mathrm{kV}$ (equipped with four Bruker silicon drift detectors). High-angle annular dark-field scanning transmission electron microscopy imaging (HAADF-STEM) yields chemically sensitive images with high spatial resolution. The acquisition time for a 1024 px by 1024 px map was 1000 s with a resolution of $14 \mathrm{~nm} / \mathrm{px}$. Image stitching was used to extend the field of view. Nine composition maps were stitched together to cover the whole SOFC structure with all relevant interfaces in one single image. Composition quantification was carried out with the Bruker Esprit software using the standardless Cliff-Lorimer thin-film method. The oxygen signal was excluded from quantification due to strong absorption of lowenergy X-rays. SAED patterns for crystal structure analyses were also taken in the Tecnai Osiris ChemisTEM.

Electron transparent cross-sectional TEM specimens were prepared by FIB-based techniques and by conventional mechanical sample preparation (including grinding, dimpling and ion-etching).

\section{Results and discussion}

\section{Optical microscopy}

Optical microscopy allows true color images (cf. Fig. 2a). The thickness of the substrate can be determined as $1200-1250 \mu \mathrm{m}$, while the thicknesses of the much thinner cathode, electrolyte and anode layers cannot be determined. Macroscopic failures like cracks and fissures or other large-scale inhomogeneities which are one of the abovementioned concerns of co-firing are absent in this part of Sample 1A. Offering a very low preparation effort, OM is helpful for a first, rough quality control of the sample.
$\mu-\mathrm{CT}$

$\mu$-CT offers nondestructive sample testing and allows one to distinguish the features of the thick, highly porous substrate and all functional layers (cf. Fig. 2b). With a voxel size of $500 \mathrm{~nm}$, a total volume sector with an edge length of approximately $600 \mu \mathrm{m}$ was scanned. The denser the materials, the more the surrounding layers within the beam path influence the scan results of the region of interest. The thick substrate is particularly well qualified to be examined by $\mu$-CT because there is no need to differentiate between multiple material phases and since the pore sizes in the $10 \mu \mathrm{m}$ range are sufficiently large. A raw 2D grayscale image of the scan can be seen in Fig. 3a. The grayscale value increases with density: epoxyfilled pores are black (lightest phase), the silicate support is gray, impurities appear bright. Figure $3 \mathrm{~b}$ shows the reconstructed representative volume element of $0.18 \mathrm{~mm}^{3}$ (voxel size $500 \mathrm{~nm}$ ). Here, the focus is set on the pore phase (rendered in brown). The material phase is transparent. Microstructural parameters such as pore fraction, $\varepsilon_{\text {pore }}$ and tortuosity factor of the pore phase, $\tau_{\text {pore }}$ can be computed. Since different methods and definitions exist for calculating tortuosity, it should be made clear that the effective media definition $\left(D_{\text {eff }}=\varepsilon \cdot \tau^{-1} \cdot D\right.$, see, e.g., $\left.[35,38]\right)$ was used here for the calculation. This approach should not be confused with other approaches such as geometric tortuosity. The tortuosity factor is here calculated with an in-house Matlab implementation of a finite element method (FEM) model which uses the reconstructed structure as computational grid; more details on this can be found in [35]. Calculations reveal a preferential pore orientation parallel to the functional layers, resulting in a higher tortuosity of the pores in gas transport direction $\left(\tau_{\text {pore }, \|}\right)$. This may lead to increased gas diffusion losses. The obtained CT data can be used as a basis for modeling these transport processes and performance estimation (cf. section "Cathode gas diffusion polarization").

Inhomogeneities such as deviations in layer thickness or $\mu \mathrm{m}$-sized, larger particles embedded in or added to the functional layers can also be visualized by $C T$. Figure $2 b$ shows one example of a $\mu \mathrm{m}$-sized out-sized particle $(>20 \mu \mathrm{m})$ within the CCL that was revealed by CT. In a next step, these particles were identified by SEM-EDXS as LSM. We suspect the origin in particle size inhomogeneities in the LSM powder (either remnants from the milling process, or 
Figure 2 Overview: a true color image of the whole cross section (Sample 1A) represented by optical microscope (OM).

b Magnified region of functional layers with superimposed images of similar regions acquired with $\mu$-CT (Sample 1B), SEM (Sample 1A) and STEM (Sample 1B). The figure gives an idea of the image information that can be achieved with the different methods.

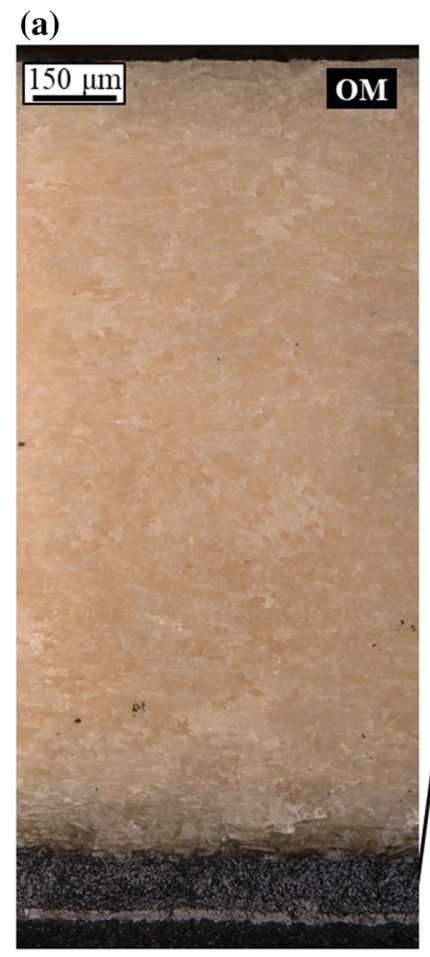

(b)

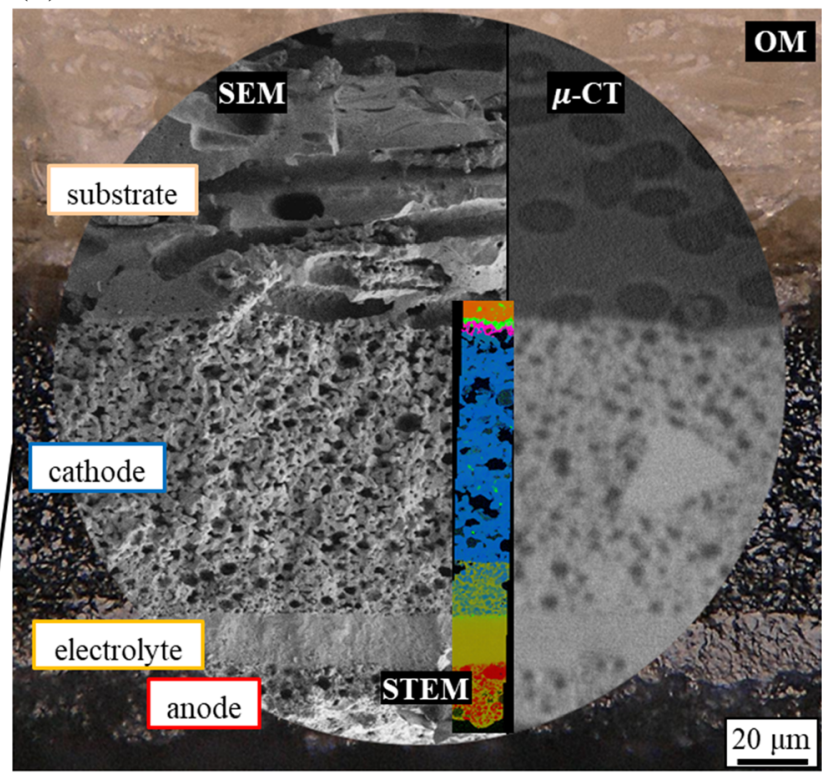

intentional inclusions, to affect shrinkage behavior during sintering). Spatial CT analysis helps to reveal such particles that might not be noticed when inspecting the $2 \mathrm{D}$ cross section.

Unfortunately, the edges of features in CT images are blurred, especially when investigating particles smaller than a few micrometers. The boundaries between particles can only be approximated which leads to a degree of segmentation uncertainty. This hinders the separation of pores and material phases within CCL, CFL and anode. While large pores are visible, pores $<1 \mu \mathrm{m}$ are not reliably detected, which impedes phase assignment. In addition, the average atomic number (LSM: 20.2, YSZ: 18.6) and the X-ray absorption rates are too similar to allow material phases differentiation in the CFL.

In general, $\mu-\mathrm{CT}$ allows good results when investigating the macroscopic features of the inert substrate but fails to resolve the fine particle/pore structures within the functional layers. Therefore, the authors do not advise the use of $\mu$-CT to determine the microstructural parameters of SOFC functional layers.

\section{FIB-SEM tomography}

Figure 4a shows a secondary-electron SEM image from a FIB-milled electrolyte/anode cross section. The anode consists of rather uniform YSZ particles, but offers bimodal size distributions of nickel particles (small, dense particles and larger particles with inner porosity) and pores (large, round pores and smaller, twisted pores). Imaging with the TLD (using primary electrons with an energy of $3 \mathrm{keV}$ ) generates strong contrast between YSZ (gray), Ni (bright) and pores/epoxy (black), and also allows clear differentiation between the three phases. Figure $4 \mathrm{~b}$ shows a $3 \mathrm{D}$ reconstruction with a large volume of $12,792 \mu \mathrm{m}^{3}$, which allows reliable extraction of microstructural parameters (cf. Table 2). The necessitated voxel size of $30 \mathrm{~nm}$ fails to show the nanoscale $\mathrm{MnO}_{\mathrm{x}}$ precipitates that were observed by STEM-EDXS (cf. section "STEM-EDXS").

\section{STEM-EDXS}

A cross-sectional SEM image and a corresponding color-coded element distribution map of the entire SOFC structure obtained by STEM-EDXS (nine stitched mappings, cf. section "STEM-EDXS") are shown in Fig. $5 a, b$, respectively. Figure $5 c$ shows SAED patterns confirming the crystal structure of secondary 
(a)

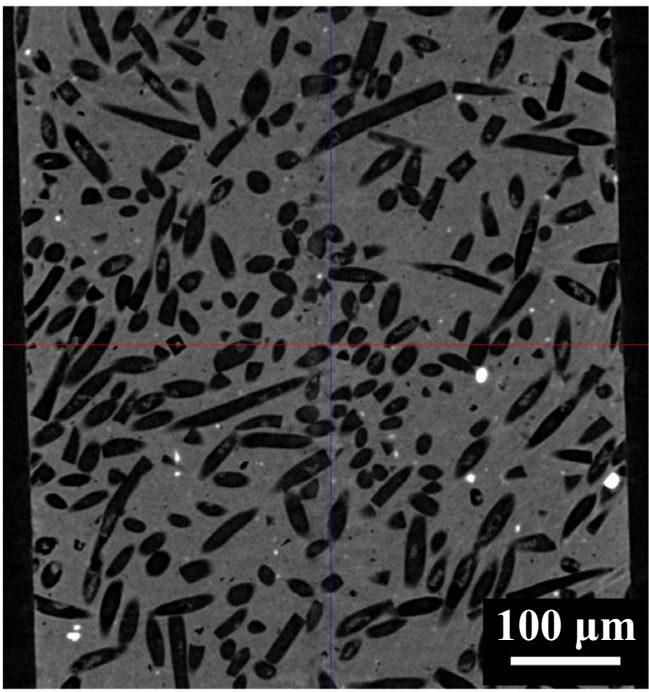

gas transport direction

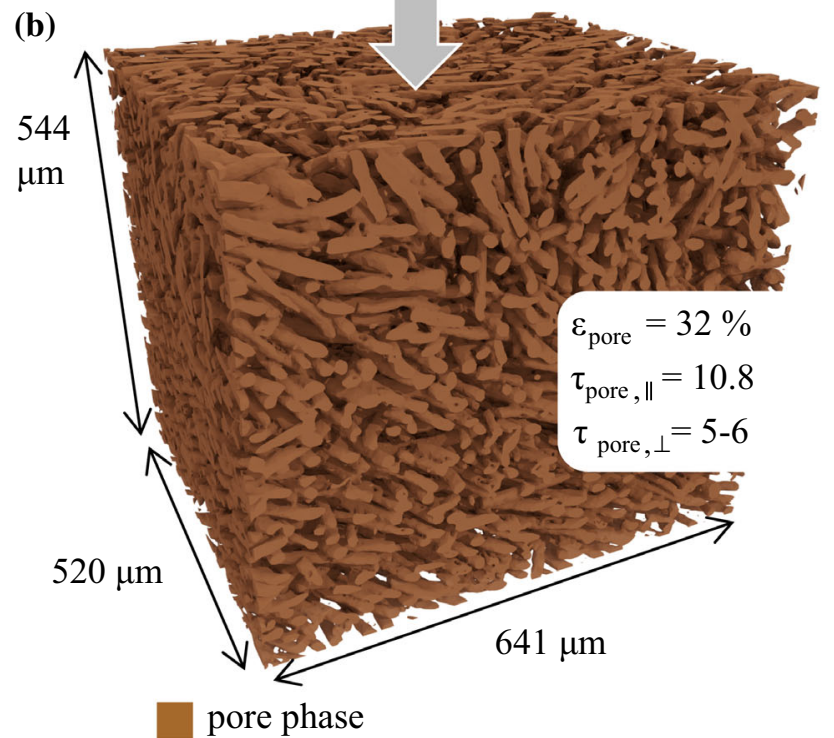

Figure 3 a Raw 2D image of the silicate support dataset obtained by $\mu$-CT (Sample 1B). b Reconstructed 3D-structure. Tortuosity calculations show a higher pore tortuosity factor in transport direction $\tau_{\text {pore, } \|}$ compared to in-plane pores $\tau_{\text {pore }, \perp}$. The range of values for $\tau_{\text {pore }, \perp}$ corresponds to the calculated tortuosity factor between the sides of the reconstructed volume ( $x$ - and $y$-direction) that are not in transport (z-) direction.

phases at the substrate/cathode interface. The following section lays special emphasis on reaction phases resulting from high-temperature co-sintering.

Cathode side: at the interface between substrate and the CCL, two layers are observable and they are characterized by high concentrations of either $\mathrm{Zn} /$ Mn (green) or Si (pink). SAED analysis (cf. Fig. 5c) (a)

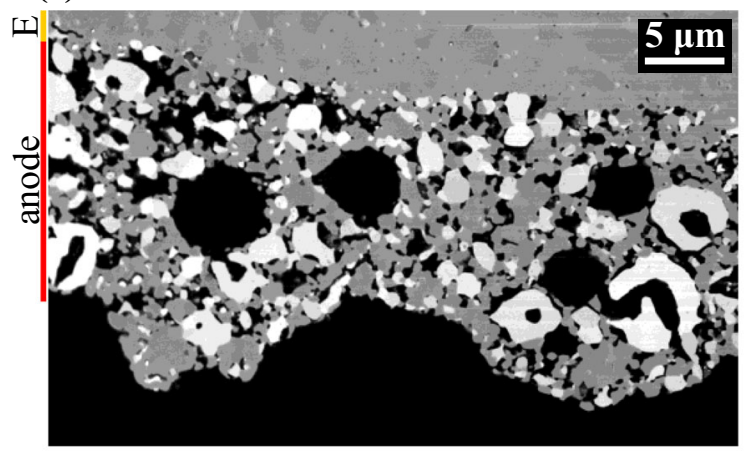

(b)

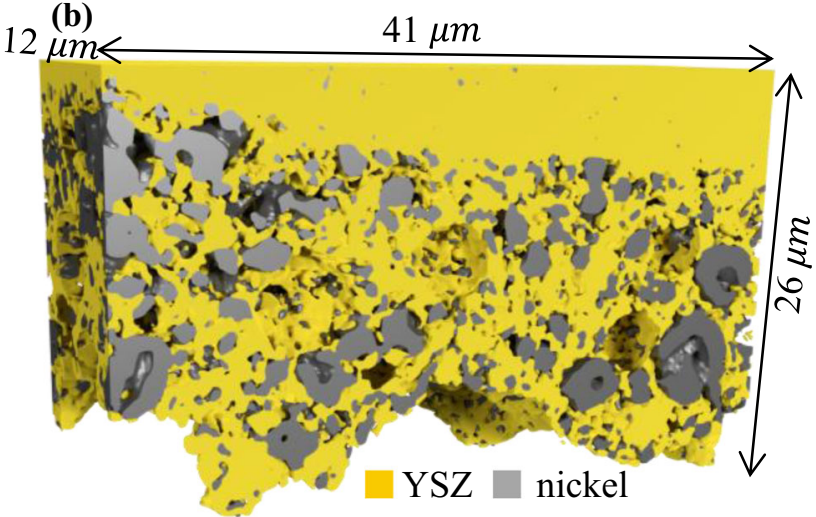

Figure 4 a Secondary-electron SEM image (Sample 1B, TLD, $3 \mathrm{keV}$ ) of the anode including the electrolyte/anode interface with pore phase (black), YSZ (gray) and nickel (bright). b Corresponding reconstructed volume.

reveals the crystal structures of these layers and allows phase identification. The $\mathrm{Zn} / \mathrm{Mn}$-rich layer was identified as cubic spinel $\mathrm{ZnMn}_{2} \mathrm{O}_{4}$ (crystal space group Fd-3 m, lattice parameter: $a=0.84 \mathrm{~nm}$ ) and the Si-rich layer as apatite $\mathrm{Sr}_{2} \mathrm{La}_{8}\left(\mathrm{SiO}_{4}\right)_{6} \mathrm{O}_{2}$ (crystal space group P63 $/ \mathrm{m}$, lattice parameter: $a=0.9705 \mathrm{~nm}$, $c=0.7241 \mathrm{~nm})$.

In addition to that, sub- $\mu$ m-sized $\mathrm{ZnMn}_{2} \mathrm{O}_{4}$ precipitates spread out into the entire CCL volume, as indicated by the green arrows in Fig. 5b. In contrast, no $\mathrm{ZnMn}_{2} \mathrm{O}_{4}$ precipitates were found within the CFL volume, but a distinctive number of $\mathrm{ZnMn}_{2} \mathrm{O}_{4}$ precipitates were found at the interface between CFL and electrolyte (cf. Fig. 5d). On the other hand, the CCL and the CFL are free of Si-rich precipitates that are known to have a strong impact on cell performance.

It is assumed that both secondary phases, $\mathrm{ZnMn}_{2} \mathrm{O}_{4}$ and $\mathrm{Sr}_{2} \mathrm{La}_{8}\left(\mathrm{SiO}_{4}\right)_{6} \mathrm{O}_{2}$, are formed during high-temperature co-sintering. A solid-state diffusion of zinc and silicon cations from the support and 
(a)

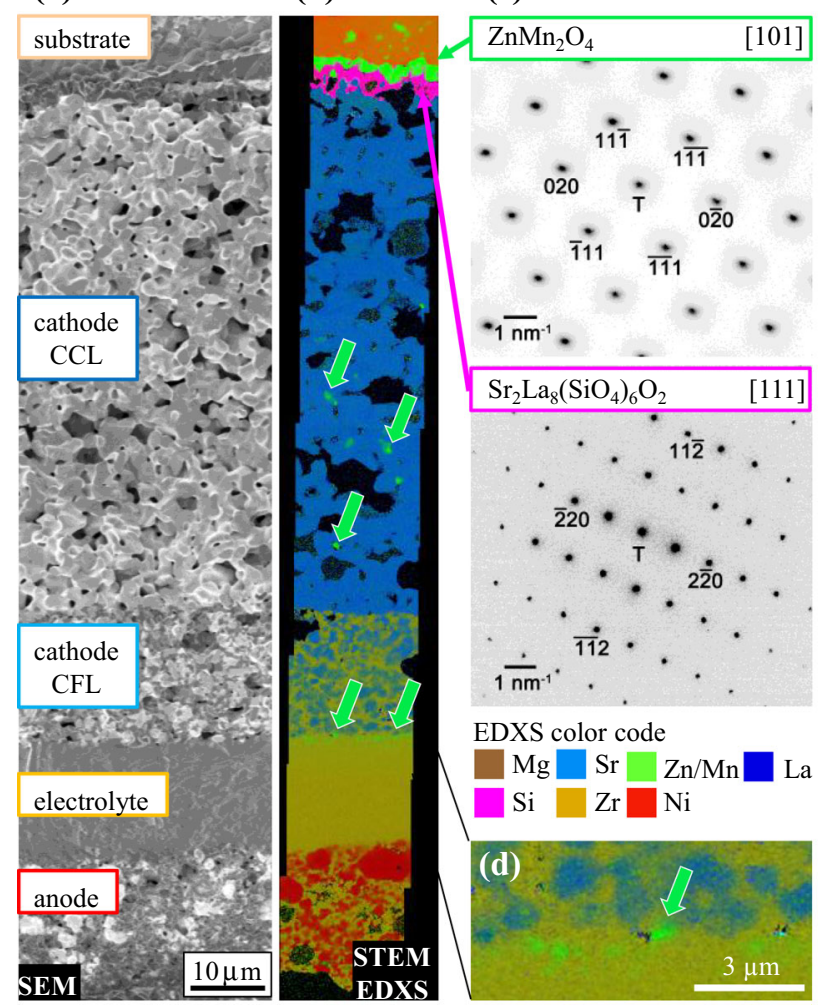

Figure 5 a Cross-sectional SEM image (Sample 1A). b Corresponding color-coded STEM-EDXS element distribution map (Sample 1B). The secondary phases $\mathrm{ZnMn}_{2} \mathrm{O}_{4}$ and $\mathrm{Sr}_{2} \mathrm{La}_{8}\left(\mathrm{SiO}_{4}\right)_{6} \mathrm{O}_{2}$ were found at the interface of $\mathrm{CCL}$ and substrate. The crystalline structures of the secondary phases were confirmed by SAED taken for $\mathrm{ZnMn}_{2} \mathrm{O}_{4}$ in the [101] zone axis and for $\mathrm{Sr}_{2} \mathrm{La}_{8}\left(\mathrm{SiO}_{4}\right)_{6} \mathrm{O}_{2}$ in the [111] zone axis (c). Various $\mathrm{ZnMn}_{2} \mathrm{O}_{4}$ precipitates (green arrows) are found within the entire CCL (b) and are accumulated at the interface between CFL and electrolyte (d).

lanthanum, strontium and manganese from the CCL is probably the mechanism that forms the spinel and apatite layers between the support and CCL. In addition, the $\mathrm{Zn}$ spreads out over a distance of up to $90 \mu \mathrm{m}$ via gas diffusion through the open pore phase of both cathodic layers and precipitates as $\mathrm{ZnMn}_{2} \mathrm{O}_{4}$ within the CCL and at the CFL/electrolyte interface. The assumption that these mechanisms take place only during co-firing is supported by our finding that neither composition, location nor the amount of either secondary phases change between the "after co-firing" and "after operating" states (the full findings would exceed the scope of this paper).

The distinct reactivity between substrate and cathodic layers called for an investigation of the composition. The nominal elemental composition of
LSM and YSZ was compared with the measured composition of both phases within the CCL and the electrochemically active CFL of Sample 1B. Please note that a quantification of low-energy $\mathrm{X}$-rays of oxygen was omitted due to the large quantification error from strong absorption in the TEM sample. Table 1 clearly indicates deviations from the nominal LSM stoichiometry for the elements $\mathrm{La}, \mathrm{Sr}$, and $\mathrm{Mn}$ (for both CCL and CFL). Especially, the Mn cation concentration is more than $30 \%$ lower than expected (ratio $(\mathrm{La}+\mathrm{Sr}$ )/Mn in CFL: nominal: 0.98, measured: 1.28). The elemental composition of the YSZ phase within the CFL is also different, compared to nominal stoichiometry: 4 at $\%$ of $\mathrm{Mn}$ and 3 at. $\%$ of $\mathrm{La}$ are found. Although the EDXS quantification error can be up to $10 \%$, the findings confirm the high volatility of manganese during co-firing. The change in LSM stoichiometry alters the electrical and electrochemical characteristics of the CFL, yet no quantitative experiments have so far been performed.

Electrolyte: a STEM-EDXS elemental distribution analysis of the YSZ electrolyte validates the diffusion of $\mathrm{Mn}$ into the electrolyte with a linear decrease from 3 at.\% $\mathrm{Mn}$ at the cathode side to $<1$ at.\% $\mathrm{Mn}$ at the anode side. The elements $\mathrm{Mg}, \mathrm{Sr}$ and $\mathrm{Si}$ are below the detection limit $(\mathrm{Mg} / \mathrm{Sr}<0.5$ at.\%, $\mathrm{Si}<1.5$ at.\%). The Mn content correlates directly with the YSZ grain size and the electrolyte density. It is assumed that $\mathrm{Mn}$ promotes YSZ sintering by accelerating grain growth and densification, which is consistent with the literature [39, 40]. This is beneficial for lower co-firing temperatures and ultimately for long-term ionic conductivity (see below). YSZ with an yttria content $>10 \mathrm{~mol} . \%$ is permanently stabilized in the cubic phase with a high ionic conductivity, whereas 8YSZ is only partially stabilized [41, 42]. During aging, cubic $8 Y S Z$ is partially transformed into $\mathrm{t}^{\prime \prime}-\mathrm{ZrO}_{2}$ with a lower ionic conductivity. We examined YSZ crystal structure changes across the functional layers (from the cathode to the anode side) by SAED patterns and demonstrate the effect of the Mn concentration on the YSZ crystal structure. Figure 6a shows a SAED pattern in [111] zone-axis orientation taken in a YSZ grain in the CFL. The pattern is compatible with the cubic crystal structure (fluorite, crystal space group Fm3m, lattice parameter: $a_{\mathrm{c}}=0.512 \mathrm{~nm}$ [42]). The same YSZ crystal structure is found in the electrolyte close to the CFL/electrolyte interface (cf. Fig. 6b) and in the center region of the electrolyte (Fig. 6c). Additional reflections are clearly recognizable in 
Table 1 Nominal and measured composition of the LSM and YSZ phases in the cathode

Figure 6 Low-magnification SEM image (Sample 1B) and SAED patterns of YSZ in the cubic [111] zone-axis orientation acquired in different regions of the SOFC structure: $\mathbf{a}-\mathbf{c}$ reflections corresponding to the cubic structure at the cathode side and within the electrolyte. $\mathbf{d}-$ e Cubic and additional tetragonal reflections (marked by red circles) reveal the occurrence of the $t^{\prime \prime}$ YSZ phase in the anode and electrolyte close to the anode.

\begin{tabular}{|c|c|c|c|c|c|}
\hline & \multicolumn{5}{|c|}{$\begin{array}{l}\text { STEM-EDXS } \\
\text { Concentration/at.\% }\end{array}$} \\
\hline & \multicolumn{3}{|c|}{ LSM phase } & \multicolumn{2}{|c|}{ YSZ phase } \\
\hline & Nominal & Measured (CCL) & Measured (CFL) & Nominal & Measured (CFL) \\
\hline Lanthanum & 39.2 & 42 & 42 & 0 & 3 \\
\hline Strontium & 9.8 & 10 & 11 & 0 & 0 \\
\hline Manganese & 50 & 42 & 42 & 0 & 4 \\
\hline Yttrium & 0 & 0 & 0 & 16 & 13 \\
\hline Zirconium & 0 & 1 & 2 & 84 & 77 \\
\hline Other & 0 & 5 & 3 & 0 & 3 \\
\hline
\end{tabular}

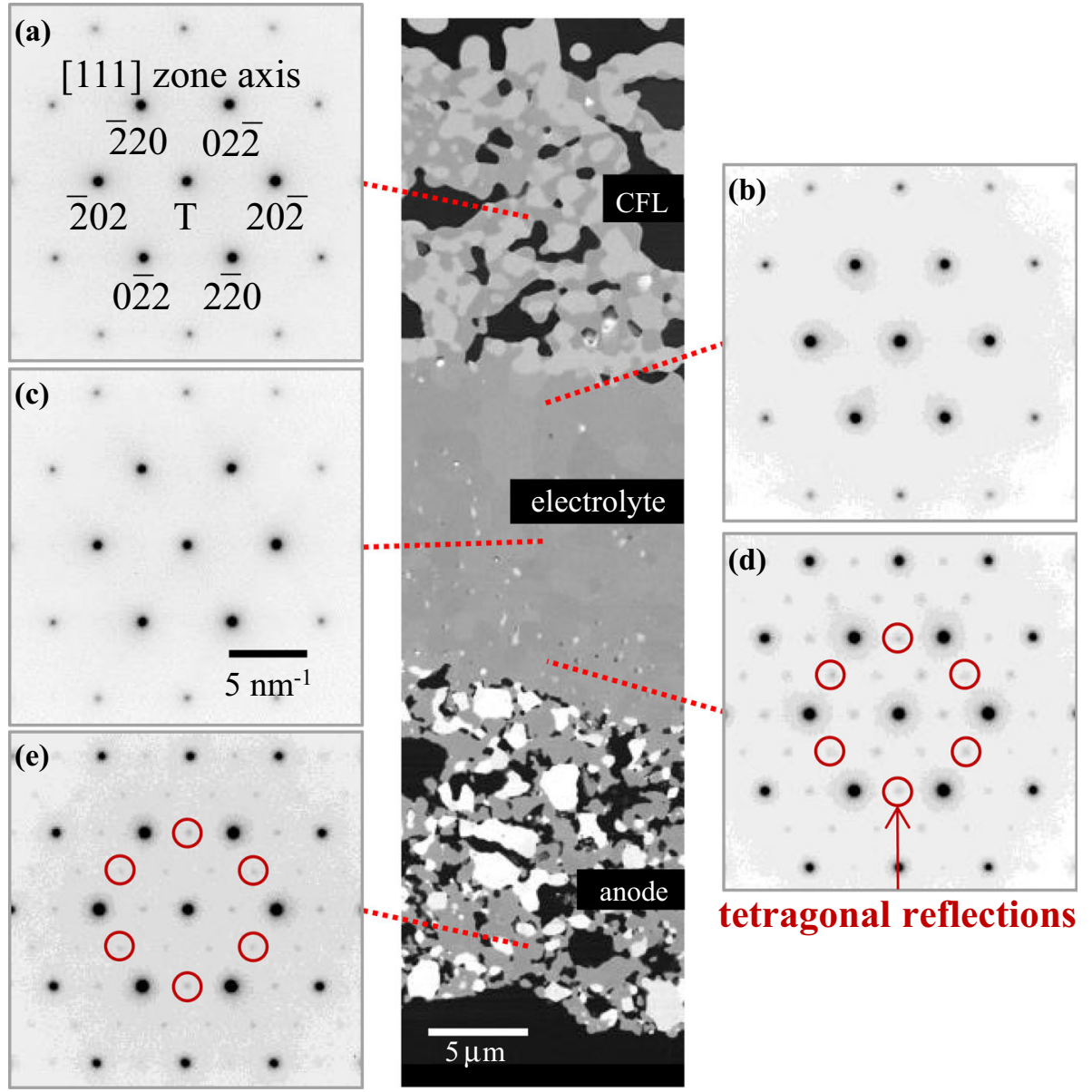

SAED patterns taken close to the electrolyte/anode interface and in anode YSZ grains. These reflections can be assigned to the $\mathrm{t}^{\prime \prime}-\mathrm{YSZ}$ phase $\left(\mathrm{P}_{2} / \mathrm{nmc}\right.$ [43]). In contrast to the equilibrium tetragonal phase, the $c$ / $a$ ratio of the $c$ and $a$ lattice parameters in the metastable $\mathrm{t}^{\prime \prime}$-phase is 1 .

A comparison of the $\mathrm{Mn}$ distribution across the electrolyte with the YSZ crystal structure indicates that Mn stabilizes the cubic YSZ phase (in agreement with the literature [44]). Despite a lower initial ionic conductivity, due to manganese, when compared to pure 8 YSZ $[40,45,46]$ one consequence could be a better long-term conductivity since the formation of the above-mentioned low-conductivity $t^{\prime \prime}$-phase is delayed. However, the presence of manganese within the electrolyte must be considered carefully. Malzbender et al. observed stack failure after 19,000 h of operation due to electrolyte fracture. Manganese 
accumulation at the grain boundaries and subsequent crack growth along these boundaries were identified as a possible reason for failure [47].

Anode: STEM-EDXS also detected manganese at the anode side (cf. Fig. 5, small green regions). Instead of being dissolved in the YSZ grains, $\mathrm{Mn}$ is distributed as $\mathrm{MnO}_{\mathrm{x}}$ precipitates (sizes from a few tens to a few hundred nanometers). SAED reveals the cubic $\mathrm{NaCl}$ structure $(a=0.44 \mathrm{~nm})$ which is characteristic for $\mathrm{MnO}$. However, additional superstructure reflections and reduced oxygen content compared to $\mathrm{MnO}$ indicate oxygen-deficient $\mathrm{MnO}_{x}(x<1)$. Due to the low $\mathrm{Mn}$ concentration within the electrolyte at the anode side, it is assumed that manganese diffuses through the gas phase from the cathode to the anode during co-sintering. The impact on performance (e.g., blocking of triple-phase boundaries between nickel, YSZ and gas phase) may be important and has to be further investigated.

\section{Correlation of FIB-SEM and STEM-EDXS}

The following section shows how information obtained by STEM-EDXS (cf. Figure 5) can be used to enhance information from FIB-SEM tomography. We now focus on the substrate/CCL and CFL/electrolyte interfaces.

Substrate/CCL interface: Results from STEM-EDXS (cf. Figure 5) allow the correlation of SEM grayscale information and material composition. Figure 7 (left side) shows the SEM contrast of the substrate/CCL interface region obtained by secondary-electron SEM imaging with the TLD (Zeiss 1540XB, $1.3 \mathrm{keV}$ ). These

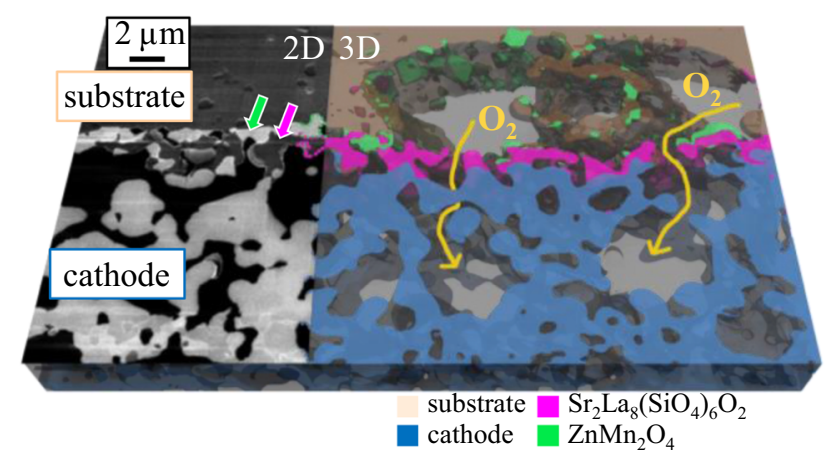

Figure 7 Primary and secondary phases at the substrate/CCL interface of Sample 1B. Raw SEM grayscale image (left) and reconstructed volume (right). Elemental information from STEMEDXS allows segmentation of the secondary phases $\mathrm{ZnMn}_{2} \mathrm{O}_{4}$ and $\mathrm{Sr}_{2} \mathrm{La}_{8}\left(\mathrm{SiO}_{4}\right)_{6} \mathrm{O}_{2}$. The black pore phase (left) is rendered transparent in the right image. imaging conditions are composition sensitive and reveal regions with different phases. Besides the black pores, two additional phases (bright next to the support and dark next to the cathode) can be recognized between the dark support and the bright CCL. Elemental information obtained with STEM-EDXS allows us to correlate the bright secondary phase with $\mathrm{ZnMn}_{2} \mathrm{O}_{4}$ and the darker one with $\mathrm{Sr}_{2} \mathrm{La}_{8}\left(\mathrm{SiO}_{4}\right)_{6} \mathrm{O}_{2}$. We note that SEM imaging with the ETD (not shown here) does not show material contrast of the secondary phases.

The presented findings allow primary- and secondary-phase segmentation for FIB-SEM tomography, as indicated by color coding in Fig. 7 (here with a large total volume of $5641 \mu \mathrm{m}^{3}$ ). The reconstructed volume (right side of Fig. 7) shows the arrangement of $\mathrm{ZnMn}_{2} \mathrm{O}_{4}$ (green) and $\mathrm{Sr}_{2} \mathrm{La}_{8}\left(\mathrm{SiO}_{4}\right)_{6} \mathrm{O}_{2}$ (pink) and reveals gaps in the layers of the two secondary phases. The continuous network of pores across the substrate/CCL interface provides $\mathrm{O}_{2}$ diffusion pathways. Please note, with provided sufficient gas transport across the interface, these secondary phases do not impede the cell performance of the inertsubstrate-supported cells (unlike in anode or metalsupported cells). Therefore, the main interest is whether secondary phases contribute to an increase in gas diffusion losses. An exceptionally dense layer of secondary phases would block oxygen across the interface. Fortunately, the marked paths in Fig. 7 indicate that open pores are available. This suggests that the secondary phases do not impact oxygen diffusion or cell performance.

In order to unambiguously evaluate the gas diffusion losses due to the secondary phases, the reconstructed volume was imported into COMSOL Multiphysics. In contrast to 2D FEM simulations of entire stack layers (see [48]), spatially resolved 3D FEM simulations are restricted to smaller volumes as shown in Fig. 7. Subsequently, the drop of oxygen partial pressure, $p \mathrm{O}_{2}$, across the interface was determined by FEM simulations. Depending on wall distance, a spatial differentiation between ordinary and Knudsen diffusion coefficients was implemented. The concentration overpotential resulting from the difference in partial pressure between the gas atmospheres of substrate and cathode can be derived from the Nernst equation and calculated via $[49,50]$ :

$$
\eta_{\text {conc }}=\frac{\mathrm{RT}}{4 \mathrm{~F}} \ln \left(\frac{\mathrm{pO}_{2, \text { in }}}{\mathrm{pO}_{2, \text { out }}}\right)
$$


with ideal gas constant, $R$, Faraday constant, $F$, oxygen partial pressure, $p \mathrm{O}_{2}$, and temperature, $T$. The resulting area specific gas diffusion resistance is calculated as $A S R_{\text {Gas }}=\eta_{\text {conc }} / j<1 \mathrm{~m} \Omega \mathrm{cm}^{2}\left(T=750{ }^{\circ} \mathrm{C}\right)$ at a current density of $1 \mathrm{Acm}^{-2}$ neglecting strong nonlinear dependencies of the diffusion polarization. As the losses are even smaller for lower current densities, one can say that the secondary phases between support and CCL do not significantly influence cell performance. Therefore, this interface is not considered in the calculation of cathode gas diffusion polarization (cf. section "Cathode gas diffusion polarization").

Cathode and CFL/electrolyte interface: Fig. 8 presents backscattered-electron SEM images and a large reconstructed volume of the cathode and CFL/electrolyte interface. The SEM images in Fig. 8a were taken with the ICD at $5 \mathrm{keV}$ and show high contrast between the different phases (especially between LSM and 8YSZ). Exploiting the STEM-EDXS results (cf. Fig. 5), the SEM contrast of all phases can be determined with black contrast for pores/epoxy and increasing brightness for $\mathrm{ZnMn}_{2} \mathrm{O}_{4}, 8 \mathrm{YSZ}$ and LSM. Unfortunately, a decrease in brightness is observed toward the edges of the low-magnification image in Fig. 8a, which is disadvantageous for segmentation in FIB-SEM tomography. This problem is avoided by backscattered-electron imaging with the MD (5 keV) which yields images without contrast change over large regions of interest. The contrast between the phases is a bit lower compared to center regions of the ICD but good enough to allow a reliable segmentation.

Figure $8 \mathrm{~b}$ presents a $3 \mathrm{D}$ reconstruction of the phase distribution in a large volume of the cathode and across the CFL/electrolyte interface $\left(42767 \mu \mathrm{m}^{3}\right.$ with $30 \mathrm{~nm}$ voxel size). FIB-SEM tomography confirms the results of STEM-EDXS regarding the location of $\mathrm{ZnMn}_{2} \mathrm{O}_{4}$ precipitates, which were found throughout the whole CCL volume (dark gray and green spots in Fig. 8a, b, respectively). Precipitates are located between pores and LSM, and not inside LSM particles. This indicates $\mathrm{Zn}$ diffusion during co-sintering via gas phase through the pores. The zinc reacts with manganese from the cathode to form $\mathrm{ZnMn}_{2} \mathrm{O}_{4}$. (a)

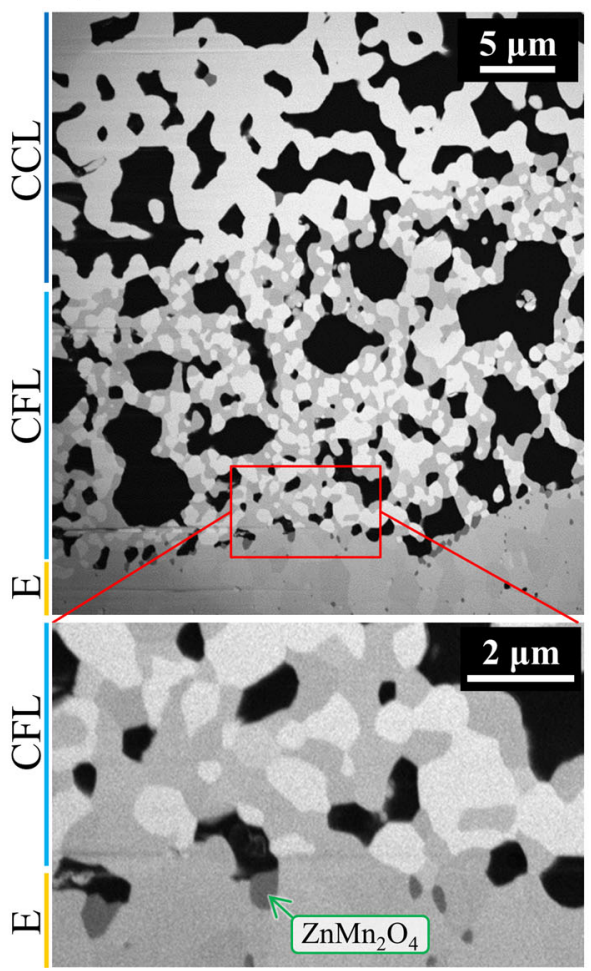

(b)

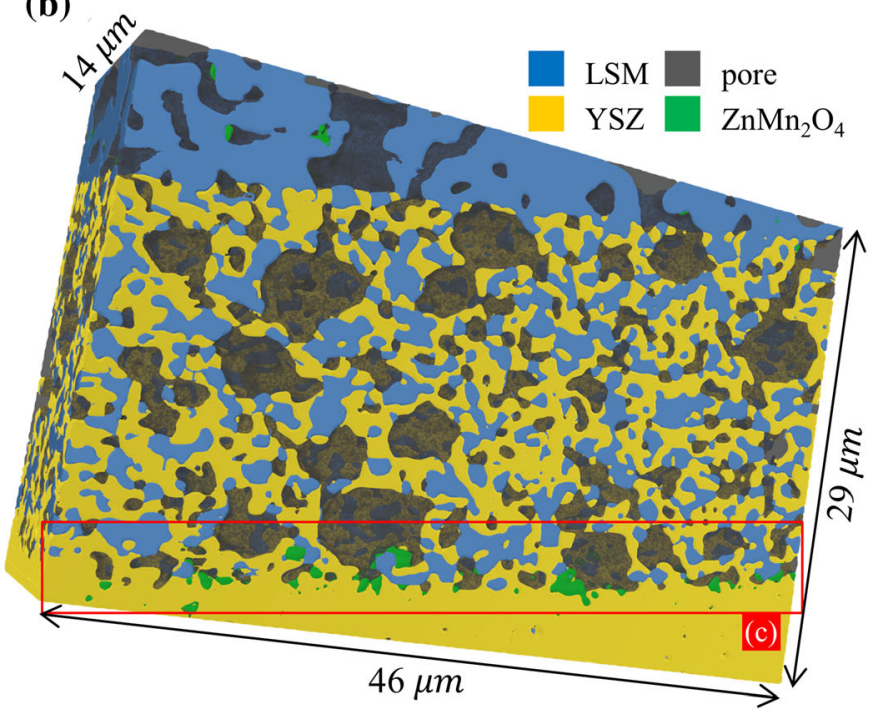

(c)

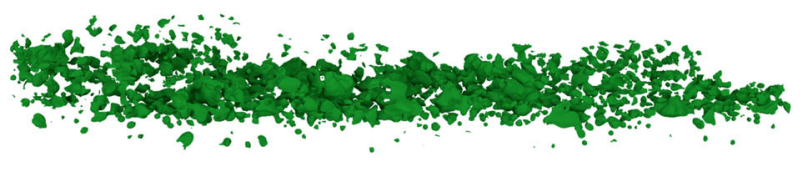

Figure 8 a Backscattered-electron SEM images of the cathode and CFL/electrolyte interface (Sample 1B, ICD, $5 \mathrm{keV}$ ). b Reconstructed volume and color-coded distribution of all phases and (c) distribution of the secondary phase, $\mathrm{ZnMn}_{2} \mathrm{O}_{4}$ precipitates at the CFL/electrolyte interface. 
The evaluated microstructural parameters can be found in Table 2. Besides material fraction, $\varepsilon$, and tortuosity, $\tau$, we also calculated the triple-phase boundary length, $l_{\mathrm{TPB}}$. The full parameter set allows future implementation of a transmission line model (TLM) to describe the cathode polarization resistance (in analogy to a TLM of the Ni/YSZ anode shown in [51]). A detailed comparison of modeled and measured impedance data would be beyond the scope of this paper and will be published soon.

The presence of accumulated $\mathrm{ZnMn}_{2} \mathrm{O}_{4}$ precipitates at the CFL/electrolyte interface revealed by STEM-EDXS (cf. Figure 5) is then confirmed in Fig. $8 \mathrm{~b}$ and highlighted in Fig. $8 \mathrm{c}$, where only the $\mathrm{ZnMn}_{2} \mathrm{O}_{4}$ precipitates at the CFL/electrolyte interface are shown. Studies on other cell systems have shown that a discontinuous layer of secondary phases can be tolerated in some cases as the performance is still good $[20,21]$. $\mathrm{ZnMn}_{2} \mathrm{O}_{4}$ was also found within the electrolyte at YSZ triple points close to the cathode interface (dark gray spots in magnified SEM image in Fig. 8a). Almost no additional $\mathrm{ZnMn}_{2} \mathrm{O}_{4}$ was found within the CFL. It would become critical if triple-phase boundaries (regions where the electronic, ionic and the gaseous transport paths interact) were blocked by $\mathrm{ZnMn}_{2} \mathrm{O}_{4}$, as oxygen could not be incorporated into the YSZ. This has not yet been observed.

Activation of the LSM/YSZ cathode [29, 52, 53] enhances performance during cathodic current loading and is typically attributed to microstructural changes of the LSM near the triple-phase boundaries and improvement of LSM surface kinetics. Additionally, small $\mathrm{ZnMn}_{2} \mathrm{O}_{4}$ precipitates that cannot be resolved by SEM imaging could agglomerate with time. As a result, the surface area covered with $\mathrm{ZnMn}_{2} \mathrm{O}_{4}$ would decrease. This would facilitate the incorporation of oxygen and therefore improve cell performance at the beginning of operation. The cathode activation due to current load would be superimposed. In this case, to allow a prediction further investigations monitoring cathode performance over time would have to be performed on cells with and without secondary phases.

\section{Cathode gas diffusion polarization}

The determined microstructural parameters can be used to calculate the area specific gas diffusion polarization on the cathode side. Gas diffusion is regarded as a separate, non-coupled process, because the diffusion distance in the substrate and in the cathode is considerably higher than the penetration depth of the electrochemical reaction [50]. The area specific cathode gas diffusion resistance $\left(A S R_{\mathrm{Gas}}\right)$ can be calculated as follows [54]:

$$
\begin{aligned}
A S R_{\mathrm{Gas}}= & \left(\frac{R \cdot T}{4 \cdot F}\right)^{2} \cdot \frac{l}{p_{0}} \cdot \frac{\tau_{\mathrm{p}}}{D_{\mathrm{N}_{2}, \mathrm{O}_{2}} \cdot \varepsilon} \\
& \cdot\left(\frac{1}{p \mathrm{O}_{2} \cdot \frac{D_{\mathrm{K}, \mathrm{O}_{2}}}{D_{\mathrm{K}, \mathrm{O}_{2}}+D_{\mathrm{N}_{2}, \mathrm{O}_{2}}}}-1\right)
\end{aligned}
$$

with layer thickness $l$, standard pressure $p_{0}=1 \mathrm{~atm}$, pore tortuosity $\tau_{\mathrm{p}}$, binary gas diffusion coefficient of oxygen and nitrogen $D_{\mathrm{N} 2, \mathrm{O} 2}$ in $\mathrm{m}^{2} / \mathrm{s}$, porosity $\varepsilon$, oxygen partial pressure $p_{\mathrm{O} 2}$ and oxygen Knudsen diffusion coefficient $D_{\mathrm{K}, \mathrm{O} 2}$.

\begin{tabular}{|c|c|c|c|c|c|}
\hline & Material phase & Layer thickness $l(\mu \mathrm{m})$ & Material fraction $\varepsilon$ & Tortuosity $\tau$ & $\begin{array}{l}\text { Triple-phase boundary } \\
\text { length } l_{\mathrm{TPB}}\left(\mu \mathrm{m}^{-2}\right)\end{array}$ \\
\hline \multirow[t]{2}{*}{ Inert substrate } & Silicate & $1250^{*}$ & $0.68^{* *}$ & $<1.5^{* *}$ & \multirow[t]{2}{*}{-} \\
\hline & Pore & & $0.32^{* *}$ & $10.8^{* *}$ & \\
\hline \multirow[t]{3}{*}{ CCL } & LSM & $70^{* * *}$ & $0.64^{* * *}$ & $1.5^{* * *}$ & \multirow[t]{3}{*}{-} \\
\hline & $\mathrm{ZnMn}_{2} \mathrm{O}_{4}$ & & $0.05^{* * *}$ & - & \\
\hline & Pore & & $0.35^{* * *}$ & $2.9^{* * *}$ & \\
\hline \multirow[t]{3}{*}{ CFL } & LSM & $16^{* * *}$ & $0.29^{* * *}$ & $8.9^{* * *}$ & \multirow[t]{3}{*}{$1.6^{* * *}$} \\
\hline & YSZ & & $0.37^{* * *}$ & $2.4^{* * *}$ & \\
\hline & Pore & & $0.34^{* * *}$ & $4.3^{* * *}$ & \\
\hline \multirow[t]{3}{*}{ Anode } & Nickel & $15^{* * *}$ & $0.24^{* * *}$ & $>10^{* * *}$ & \multirow{3}{*}{$3.5^{* * *}$} \\
\hline & YSZ & & $0.34^{* * *}$ & $2.8^{* * *}$ & \\
\hline & Pore & & $0.42^{* * *}$ & $3.3^{* * *}$ & \\
\hline
\end{tabular}

Table 2 Microstructural parameters calculated from $\mathrm{OM} *, \mu-\mathrm{CT}^{* *}$ and FIB-SEM*** data set 
The Knudsen diffusion coefficient [55, 56] with pore diameter, $d_{\mathrm{p}}$, and molar mass of oxygen, $M_{\mathrm{O} 2}$, can be calculated as follows:

$D_{\mathrm{K}, \mathrm{O}_{2}}=\frac{2}{3} \cdot \frac{d_{\mathrm{p}}}{2} \cdot \sqrt{\frac{8 \cdot R \cdot T}{\pi \cdot M_{\mathrm{O}_{2}}}}$

The binary diffusion coefficients, $D_{\mathrm{N} 2, \mathrm{O} 2}$, were calculated according to the theory of Chapman and Enskog [55, 57].

Calculations on the gas diffusion resistance of the substrate/CCL interface revealed that there is no significant influence of secondary phases on total $A S R_{\text {Gas. }}$. Therefore, only substrate, CCL and CFL were considered. Results shown in Table 3 demonstrate that the main contributions to gas diffusion losses are caused by the inert substrate. Due to the manufacturing process, the substrate shows an unfavorable pore orientation, as proven by $\mu-C T$. It can be calculated that a hypothetical change in pore orientation of the inert substrate (cf. Figure 3) could reduce the $A S R_{\text {Gas,substrate }}$ from $45.7 \mathrm{~m} \Omega \mathrm{cm}^{2}$ to $21.1 \mathrm{~m} \Omega \mathrm{cm}^{2}$ at $T=750{ }^{\circ} \mathrm{C}$. The provided investigations show that only the correlation between $\mu$-CT, FIB-SEM and STEM-EDXS can allow a comprehensive examination of the processes contributing to $A S R_{\mathrm{Gas}}$.

\section{Electrode polarization resistance}

FIB-SEM results (cf. Table 2) allow modeling of anode polarization resistance using a transmission line model according to [51, 58]. The model details

Table 3 Temperature-dependent area specific gas diffusion resistance (syn. air) of inert substrate, cathode current collector layer and cathode functional layer (cf. Eq. (2))

\begin{tabular}{llll}
\hline$T$ & $\begin{array}{l}A S R_{\mathrm{Gas}} \\
\text { Tubstrate }\end{array}$ & $\begin{array}{l}\mathrm{CCL} \\
\mathrm{m} \Omega \mathrm{cm}^{2}\end{array}$ & $\begin{array}{l}\mathrm{CFL} \\
\mathrm{m} \Omega \mathrm{cm}^{2}\end{array}$ \\
\cline { 2 - 4 }${ }^{\circ} \mathrm{C}$ & $\begin{array}{l}\text { Su cm } \\
\mathrm{m} \Omega \mathrm{cm}^{2}\end{array}$ & 1.4 & 0.6 \\
\hline 600 & 43.3 & 1.5 & 0.7 \\
650 & 44.1 & 1.6 & 0.7 \\
700 & 44.9 & 1.6 & 0.7 \\
750 & 45.7 & 1.7 & 0.8 \\
800 & 46.4 & 1.8 & 0.8 \\
850 & 47.1 & 1.9 & 0.8 \\
900 & 47.8 & 1.9 & 0.9 \\
950 & 48.5 & 2.0 & 0.9 \\
1000 & 49.2 & &
\end{tabular}

are shown in Appendix A. At $T=750{ }^{\circ} \mathrm{C}$ with a fuel gas humidification of $5.5 \% \mathrm{H}_{2} \mathrm{O}$, the modeled $A S R_{\text {Anode }}$ at is $0.114 \Omega \mathrm{cm}^{2}$. This can be compared to impedance measurements: To avoid overlapping of cathode and anode processes, the modeled $A S R_{\text {Anode }}$ was compared to a symmetric anode cell fabricated under the same conditions as the full cell. With a measured $A S R_{\text {Anode }}$ of $0.113 \Omega \mathrm{cm}^{2}$, electrochemical impedance spectroscopy measurements at similar conditions are in perfect agreement with the simulations. In addition, the performance of the given unaged anode is competitive with state-of-the-art cells like the ASC of Forschungszentrum Jülich $[5,51]$.

Physicochemical meaningful modeling of the $A S R_{\text {Cathode }}$ is in principal also possible using the TLM. The fact that the LSM-YSZ composite is a dynamic system [59-61] impedes a straight forward approach as the line specific resistance changes during an initial activation phase. This current- and temperature-dependent process is often associated with microstructural changes. Combining these with expected influence of the secondary phases shown in Fig. 8 illustrates the complexity of the cathode kinetics. The authors think that this is out of the scope of this contribution. Nevertheless, this work can serve as a basis for future microstructure-based modeling of the cathode polarization resistance where several operating conditions are considered.

\section{Conclusions}

The comprehensive investigation of co-sintered, inert-substrate-supported SOFCs is a multi-scale challenge. It was shown how correlative tomography on different length scales using optical microscopy, $\mu$ CT, and FIB-SEM tomography combined with EDXSSTEM allows a meaningful understanding of cell microstructure and spatial organization of secondary phases. This provides a better understanding of the interactions and effects that influence manufacturing conditions.

The optimal fields of application for each imaging technology were demonstrated by investigating critical cell regions. While optical microscopy can be used to identify inhomogeneities or cracks, $\mu-\mathrm{CT}$ is well suited for the analysis of substrate characteristics, whereas the finer feature sizes $(<1 \mu \mathrm{m})$ of the functional layers can be better resolved by FIB-SEM 
techniques. Secondary phases are identified and correlated with the different grayscale contrasts of the SEM image by supplementary correlative investigations using EDXS-STEM, which take place on significantly smaller scales. The findings were confirmed by selected area electron diffraction (SAED) that determined the crystal structures. This advanced tomography allows further investigation, e.g., simulations show that smaller features like the secondary phases at the cathode/support interface do not have a significant effect on the gas transport at the cathode side which is dominated by the transport through the larger pores of the substrate. These multi-scale gas diffusion losses are calculated from microstructural parameters of substrate and cathode. Modeling reveals that a change of the unfavorable pore orientation within the substrate is a key aspect to reducing gas diffusion losses.

Further attention must be directed to the presence of manganese which plays an important role during co-firing. Co-sintering of all cell layers promotes a considerable $\mathrm{Mn}$ interdiffusion into different cell areas. The resulting change in LSM stoichiometry might significantly influence electrochemical performance. Manganese acts as a sintering aid within the electrolyte, contributing to the densification of the electrolyte at relatively low sintering temperatures. Besides this, it influences YSZ crystal structure: manganese-stabilized YSZ solely reveals a cubic structure, whereas YSZ containing no manganese also shows tetragonal $t^{\prime \prime}$ reflections in SAED measurements. In addition, precipitates of $\mathrm{ZnMn}_{2} \mathrm{O}_{4}$ are found within the CCL and at the interface between CFL and electrolyte. The given results of multi-scale tomography provide a broad understanding of the characteristics that influence cell performance. Microstructure-based modeling of anode polarization resistance shows first good agreement between simulation and measured data. In particular with regard to the cathode side, the influences of the secondary phases on performance have to be further evaluated. In order to guarantee a highly precise and trustful implementation of the electrochemical processes, several impedance analyses at different temperatures, gas compositions, as well as load variations have to be performed. The shown insights support future performance evaluations and recommendations for improving cell design.

\section{Acknowledgements}

Open Access funding provided by Projekt DEAL. The authors gratefully acknowledge funding by the Federal Ministry for Economic Affairs and Energy (BMWi, 03ET6101B, 03ET6101A and 03ET6101F). Sincere thanks are given to J. Packham for proofreading the manuscript.

\section{Compliance with ethical standards}

Conflicts of interest The authors declare that they have no conflict of interest.

Open Access This article is licensed under a Creative Commons Attribution 4.0 International License, which permits use, sharing, adaptation, distribution and reproduction in any medium or format, as long as you give appropriate credit to the original author(s) and the source, provide a link to the Creative Commons licence, and indicate if changes were made. The images or other third party material in this article are included in the article's Creative Commons licence, unless indicated otherwise in a credit line to the material. If material is not included in the article's Creative Commons licence and your intended use is not permitted by statutory regulation or exceeds the permitted use, you will need to obtain permission directly from the copyright holder. To view a copy of this licence, visit http://creativecommons.org/licen ses/by/4.0/.

\section{Appendix A. Transmission line model}

The transmission line model [51, 58] takes microstructure-based ionic losses through the YSZ matrix within the anode as well as a charge transfer resistance at anode's triple-phase boundaries into account. In this case, the losses of the electronic path are neglected due to the high conductivity of nickel $\left(\sigma_{\text {electron,nickel }}>10^{5} \sigma_{\text {ion,YSZ }}\right)$. The impedance of the anode electrochemistry can be calculated via:

$Z_{T L M}(\omega)=\sqrt{\zeta \cdot \chi_{1}} \cdot \operatorname{coth}\left(l \cdot \sqrt{\frac{\chi_{1}}{\zeta}}\right)$

with anode layer thickness $l$, charge transfer $\zeta$ represented by an RQ-element: 


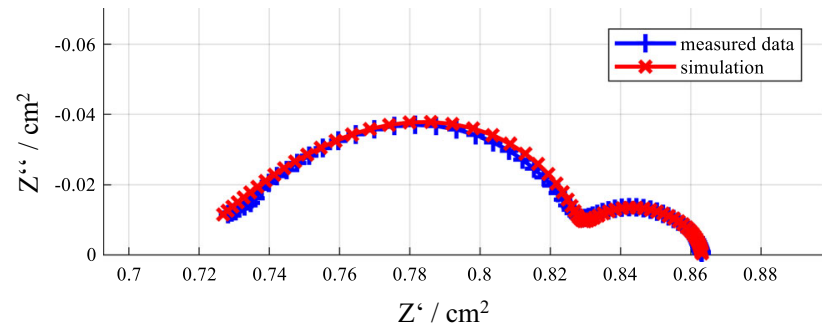

Figure 9 Nyquist plot: comparison of measured impedance of a sym. anode model cell with simulated impedance $(t=0 \mathrm{~h}$, $\mathrm{T}=750{ }^{\circ} \mathrm{C}, \mathrm{pH}_{2} \mathrm{O}=5.5 \%$, OCV). The simulation uses the TLM (cf. Eq. (4)) and the microstructural parameters shown in Table 2 (additional parameters: $L S R_{\mathrm{ct}}=158.14 \Omega \mathrm{m}$, $A_{\text {act }}=0.36 \mathrm{~cm}^{2}, \quad \sigma_{\text {ion }}=2.84 \mathrm{Sm}^{-1}$ ), as well as two RQelements referring to gas diffusion losses (right semicircle).

$\zeta=\frac{r_{c t}}{1+\left(j \omega \tau_{c t}\right)^{n}}$

$\tau_{\mathrm{ct}}$ is the time constant of the charge transfer, $r_{\mathrm{ct}}$ the charge transfer resistance containing line specific resistance $L S R_{\mathrm{ct}}$ and the microstructural parameters $l_{\text {TPB }}$ and active electrode area $A_{\text {act }}$ :

$r_{c t}=\frac{L S R_{c t}}{l_{T P B} \cdot A_{a c t}}$

Ionic transport resistance $\chi_{1}$ links microstructural parameters to ionic conductivity $\sigma_{i o n}$, which was determined using 4-point conductivity measurements:

$\chi_{1}=\frac{\tau_{Y S Z}}{\varepsilon_{Y S Z} \cdot A_{a c t} \cdot \sigma_{i o n}}$

For a more detailed explanation of the model, please refer to the publication of Dierickx et al. [51]. Figure 9 shows the good agreement between measured and simulated (without fitting) data. The right semicircle belongs to gas diffusion losses which can be mainly addressed to the measurement setup and was therefore fitted with two RQ-elements.

\section{References}

[1] Yokokawa H, Tu H, Iwanschitz B, Mai A (2008) Fundamental mechanisms limiting solid oxide fuel cell durability. J Power Sources 182:400-412. https://doi.org/10.1016/j.jpo wsour.2008.02.016

[2] Bertoldi M, Bucheli OF, Ravagni A (2017) Development, manufacturing and deployment of SOFC-based products at
SOLIDpower. ECS Trans 78:117-123. https://doi.org/10.11 49/07801.0117ecst

[3] Menzler NH, Tietz F, Uhlenbruck S et al (2010) Materials and manufacturing technologies for solid oxide fuel cells. J Mater Sci 45:3109-3135. https://doi.org/10.1007/s10853010-4279-9

[4] Borglum B, Tang E, Pastula M (2011) Development of solid oxide fuel cells at versa power systems. ECS Trans 68:63-69. https://doi.org/10.1149/1.3569979

[5] Blum L, (Bert) de Haart LGJ, Malzbender J, et al (2013) Recent results in Jülich solid oxide fuel cell technology development. J Power Sources 241:477-485. https://doi.org/ 10.1016/j.jpowsour.2013.04.110

[6] Voisard C (2005) Manufacturing solid oxide fuel cells for the sulzer hexis stationary system. Int J Appl Ceram Technol 1:31-35. https://doi.org/10.1111/j.1744-7402.2004.tb00152. $\mathrm{x}$

[7] Ivers-Tiffée E, Wersing W, Schieß1 M, Greiner H (1990) Ceramic and metallic components for a planar SOFC. Berichte der Bunsengesellschaft für Phys Chemie 94:978-981. h ttps://doi.org/10.1002/bbpc.19900940919

[8] George RA, Bessette NF (1998) Reducing the manufacturing cost of tubular solid oxide fuel cell technology. J Power Sources 71:131-137. https://doi.org/10.1016/S0378-7753(9 7)02735-3

[9] Gardner F, Day M, Brandon N et al (2000) SOFC technology development at Rolls-Royce. J Power Sources 86:122-129. https://doi.org/10.1016/S0378-7753(99)00428-0

[10] Yokokawa H, Kishimoto H, Yamaji K et al (2011) Cooperative investigations on degradation of cathode materials in segment-in-series cells by MHI. ECS Trans 35:2191-2200. h ttps://doi.org/10.1149/1.3570212

[11] Brandon NP, Blake A, Corcoran D et al (2004) Development of metal supported solid oxide fuel cells for operation at 500-600 ${ }^{\circ}$ C. J Fuel Cell Sci Technol 1:61. https://doi.org/10. $1115 / 1.1794709$

[12] Tucker MC (2017) Development of high power density metal-supported solid oxide fuel cells. Energy Technol 5:2175-2181. https://doi.org/10.1002/ente.201700242

[13] Blennow P, Hjelm J, Klemensø T et al (2011) Planar metalsupported SOFC with novel cermet anode. Fuel Cells 11:661-668. https://doi.org/10.1002/fuce.201100029

[14] Yamamoto T, Yasumoto K, Yoshikawa M et al (2013) Performance evaluations for long term durability and reliability of segment-in-series tubular type SOFCs. ECS Trans 57:763-770. https://doi.org/10.1149/05701.0763ecst

[15] Roehrens D, Han F, Haydn M et al (2015) Advances beyond traditional SOFC cell designs. Int $\mathrm{J}$ Hydrog Energy 40:11538-11542. https://doi.org/10.1016/j.ijhydene.2015.01 .155 
[16] Franco T, Haydn M, Weber A et al (2013) The status of metal-supported SOFC development and industrialization at plansee. ECS Trans 57:471-480. https://doi.org/10.1149/05 701.0471ecst

[17] Matte E, Lupetin P, Stolten D (2016) B1511 evaluation of cathode performance in co-sintered inert substrate-supported SOFC. In: Proceedings of 12th European SOFC SOE Forum B1511

[18] Matsui T, Komoto M, Muroyama H et al (2016) Degradation factors in $(\mathrm{La}, \mathrm{Sr})(\mathrm{Co}, \mathrm{Fe}) \mathrm{O}$ 3- $\delta$ cathode $/ \mathrm{Sm}_{2} \mathrm{O}_{3}-\mathrm{CeO}_{2}$ interlayer $/ \mathrm{Y}_{2} \mathrm{O}_{3}-\mathrm{ZrO}_{2}$ electrolyte system during operation of solid oxide fuel cells. J Power Sources 312:80-85. https://d oi.org/10.1016/j.jpowsour.2016.02.052

[19] Horita T, Nishi M, Shimonosono T et al (2014) Visualization of oxide ionic diffusion at SOFC cathode/electrolyte interfaces by isotope labeling techniques. Solid State Ionics 262:398-402. https://doi.org/10.1016/j.ssi.2013.12.039

[20] Wankmüller F, Szász J, Joos J et al (2017) Correlative tomography at the cathode/electrolyte interfaces of solid oxide fuel cells. J Power Sources 360:399-408. https://doi. org/10.1016/j.jpowsour.2017.06.008

[21] Szász J, Wankmüller F, Wilde V et al (2018) Nature and functionality of La $0.58 \mathrm{Sr} 0.4 \mathrm{Co} 0.2 \mathrm{Fe} 0.8 \mathrm{O} 3-\delta / \mathrm{Gd} 0.2$ Ce $0.8 \mathrm{O} 2-\delta / \mathrm{Y} 0.16 \mathrm{Zr} 0.84 \mathrm{O} 2-\delta$ interfaces in SOFCs. J Electrochem Soc 165:F898-F906. https://doi.org/10.1149/ $2.0031811 \mathrm{jes}$

[22] Kindermann L, Nickel H, Hilpert K (1996) Chemical compatibility of the $\mathrm{LaFeO} 3$ base perovskites $(\mathrm{La} 0.6 \mathrm{Sr} 0.4) \mathrm{z}-$ $\mathrm{Fe} 0.8 \mathrm{M} 0.2 \mathrm{O} 3-\delta(\mathrm{z}=1,0.9 ; \mathrm{M}=\mathrm{Cr}, \mathrm{Mn} \mathrm{Co}, \mathrm{Ni})$ with yttria stabilized zirconia. Solid State Ionics 89:215-220. h ttps://doi.org/10.1016/0167-2738(96)00366-9

[23] Yokokawa H, Sakai N, Kawada T, Dokiya M (1992) Thermodynamic stabilities of perovskite oxides for electrodes and other electrochemical materials. Solid State Ionics 52:43-56. https://doi.org/10.1016/0167-2738(92)90090-C

[24] Levy C, Zhong Y, Morel C, Marlin S (2010) Thermodynamic stabilities of $\mathrm{La}[\mathrm{sub} 2] \mathrm{Zr}\left[\begin{array}{ll}\mathrm{sub} & 2\end{array}\right] \mathrm{O}\left[\begin{array}{ll}\mathrm{sub} & 7\end{array}\right]$ and $\mathrm{SrZrO}[\mathrm{sub} 3]$ in SOFC and their relationship with LSM synthesis processes. J Electrochem Soc 157:B1597. https://d oi.org/10.1149/1.3481562

[25] Kawada T, Sakai N, Yokokawa H et al (1992) Reaction between solid oxide fuel-cell materials. Solid State Ionics 50:189-196. https://doi.org/10.1016/0167-2738(92)90218-E

[26] Liu YL, Primdahl S, Mogensen M (2003) Effects of impurities on microstructure in Ni/YSZ-YSZ half-cells for SOFC. Solid State Ionics 161:1-10. https://doi.org/10.1016/S01672738(03)00271-6

[27] Schuler JA, Wuillemin Z, Hessler-Wyser A, Van Herle J (2011) Glass-forming exogenous silicon contamination in solid oxide fuel cell cathodes. Electrochem Solid-State Lett 14:B20. https://doi.org/10.1149/1.3516622

[28] Utz A, Hansen KV, Norrman K et al (2011) Impurity features in Ni-YSZ-H2-H2O electrodes. Solid State Ionics 183:60-70. https://doi.org/10.1016/j.ssi.2010.12.014

[29] Njodzefon J-C, Maier N, Schmieg J, et al (2018) B0803 Performance and stability evaluation of a novel full- ceramic inert substrate-supported solid oxide fuel cell. In: Proceedings of the 13th European SOFC SOE Forum B0803

[30] Eisele U, Heeren I (2011) Herstellungsverfahren für eine tubulare Brennstoffzelle

[31] Schulze A, Fischer C, Schoenbauer S (2014) Brennstoffzellensystem mit verbesserter Kontaktierung

[32] Matte E, Holzlechner G, Epple L et al (2019) Impact of silicate substrate and cosintering on cathode performance in an inert substrate-supported solid oxide fuel cell. J Power Sources 413:334-343. https://doi.org/10.1016/j.jpowsour.20 18.12 .025

[33] Grimm F, Menzler NH, Guillon O (2020) Selection of cathode materials for forsterite supported solid oxide fuel cells-Part I: materials interactions. J Power Sources 451:227607. https://doi.org/10.1016/J.JPOWSOUR.2019. 227607

[34] Grimm F, Neubert M, Karl J et al (2020) Selection of cathode materials for forsterite-supported solid oxide fuel cells-Part II: electro-catalytic activity. J Power Sources 451:227811. https://doi.org/10.1016/J.JPOWSOUR.2020. 227811

[35] Joos J, Carraro T, Weber A, Ivers-Tiffée E (2011) Reconstruction of porous electrodes by FIB/SEM for detailed microstructure modeling. J Power Sources 196:7302-7307. https://doi.org/10.1016/j.jpowsour.2010.10.006

[36] Cantoni M, Holzer L (2014) Advances in 3D focused ion beam tomography. MRS Bull 39:354-360. https://doi.org/ $10.1557 / \mathrm{mrs} .2014 .54$

[37] Joos J, Ender M, Rotscholl I et al (2014) Quantification of double-layer Ni/YSZ fuel cell anodes from focused ion beam tomography data. J Power Sources 246:819-830. https://doi. org/10.1016/j.jpowsour.2013.08.021

[38] Cooper SJ, Bertei A, Shearing PR et al (2016) TauFactor: an open-source application for calculating tortuosity factors from tomographic data. SoftwareX 5:203-210. https://doi. org/10.1016/j.softx.2016.09.002

[39] Appel CC (1995) Zirconia stabilized by $\mathrm{Y}$ and Mn: a microstructural characterization. Ionics (Kiel) 1:406-413. h ttps://doi.org/10.1007/BF02375284

[40] Zhang TS, Chan SH, Wang W et al (2009) Effect of Mn addition on the densification, grain growth and ionic conductivity of pure and $\mathrm{SiO}_{2}$-containing $8 \mathrm{YSZ}$ electrolytes. 
Solid State Ionics 180:82-89. https://doi.org/10.1016/j.ssi.2 008.10 .010

[41] Peters C, Weber A, Butz B et al (2009) Grain-size effects in YSZ thin-film electrolytes. J Am Ceram Soc 92:2017-2024. https://doi.org/10.1111/j.1551-2916.2009.03157.x

[42] Butz B, Kruse P, Störmer H et al (2006) Correlation between microstructure and degradation in conductivity for cubic $\mathrm{Y}_{2} \mathrm{O}_{3}$-doped $\mathrm{ZrO}_{2}$. Solid State Ionics 177:3275-3284. http s://doi.org/10.1016/j.ssi.2006.09.003

[43] Yashima M, Sasaki S, Kakihana M et al (1994) Oxygeninduced structural change of the tetragonal phase around the tetragonal-cubic phase boundary in $\mathrm{ZrO}_{2}-\mathrm{YO}_{1.5}$ solid solutions. Acta Crystallogr Sect B: Struct Sci 50:663-672. h ttps://doi.org/10.1107/S0108768194006257

[44] Kawashima T, Hishinuma M (1998) Phase transformation of yttria-stabilized zirconia $\left(3 \mathrm{~mol} \% \mathrm{Y}_{2} \mathrm{O}_{3}\right)$ in fuel cell caused by manganese diffusion. Mater Trans, JIM 39:617-620. h ttps://doi.org/10.2320/matertrans1989.39.617

[45] Van Herle J, Vasquez R (2004) Conductivity of Mn and Nidoped stabilized zirconia electrolyte. J Eur Ceram Soc 24:1177-1180. https://doi.org/10.1016/S0955-2219(03)0047 $1-0$

[46] Kawada T, Sakai N, Yokokawa H, Dokiya M (1992) Electrical-properties of transition-metal-doped YSZ. Solid State Ionics 53-56:418-425. https://doi.org/10.1016/0167-2738(9 2) $90409-\mathrm{I}$

[47] Malzbender J, Batfalsky P, Vaßen R et al (2012) Component interactions after long-term operation of an SOFC stack with LSM cathode. J Power Sources 201:196-203. https://doi.org/ 10.1016/j.jpowsour.2011.10.117

[48] Russner N, Dierickx S, Weber A et al (2020) Multiphysical modelling of planar solid oxide fuel cell stack layers. J Power Sources. https://doi.org/10.1016/j.jpowsour.2019. 227552

[49] Primdahl S, Mogensen M (1999) Gas diffusion impedance in characterization of solid oxide fuel cell anodes. J Electrochem Soc 146:2827-2833. https://doi.org/10.1149/1. 1392015

[50] Leonide A (2010) SOFC modelling and parameter identification by means of impedance spectroscopy. KIT Scientific Publishing, Karlsruhe

[51] Dierickx S, Joos J, Weber A, Ivers-Tiffée E (2018) Advanced impedance modelling of Ni/8YSZ cermet anodes.
Electrochim Acta 265:736-750. https://doi.org/10.1016/j.el ectacta.2017.12.029

[52] Østergård MJL, Mogensen M (1993) ac Impedance study of the oxygen reduction mechanism on $\mathrm{La}_{1-x} \mathrm{Sr}_{x} \mathrm{MnO}_{3}$ in solid oxide fuel cells. Electrochim Acta 38:2015-2020. https://doi. org/10.1016/0013-4686(93)80334-V

[53] Adler SB (2004) Factors governing oxygen reduction in solid oxide fuel cell cathodes. Chem Rev 104:4791-4844. h ttps://doi.org/10.1021/cr020724o

[54] Kim J-W, Virkar AV, Fung K-Z et al (1999) Polarization effects in intermediate temperature, anode-supported solid oxide fuel cells. J Electrochem Soc 146:69. https://doi.org/ $10.1149 / 1.1391566$

[55] Cussler EL (2009) Diffusion: mass transfer in fluid systems, 3rd edn. Cambridge University Press, Cambridge

[56] Velfsink JW, van Damme RMJ, Versteeg GF, van Swaaij WPM (1995) The use of the dusty-gas model for the description of mass transport with chemical reaction in porous media. Chem Eng J 57:115-125. https://doi.org/10. 1016/0923-0467(94)02929-6

[57] Chapman S, Cowling TG, Burnett D (1990) The mathematical theory of non-uniform gases: an account of the kinetic theory of viscosity, thermal conduction and diffusion in gases, 3rd edn. Cambridge University Press, Cambridge

[58] Dierickx S, Mundloch T, Weber A, Ivers-Tiffée E (2019) Advanced impedance model for double-layered solid oxide fuel cell cermet anodes. J Power Sources 415:69-82. http s://doi.org/10.1016/j.jpowsour.2019.01.043

[59] Ivers-Tiffée E, Weber A, Schmid K, Krebs V (2004) Macroscale modeling of cathode formation in SOFC. Solid State Ionics 174:223-232. https://doi.org/10.1016/j.ssi.2004.05. 031

[60] McIntosh S, Adler SB, Vohs JM, Gorte RJ (2004) Effect of polarization on and implications for characterization of LSM-YSZ composite cathodes. Electrochem Solid-State Lett 7:A111. https://doi.org/10.1149/1.1667792

[61] Heneka MJ, Ivers-Tiffée E (2005) Degradation of SOFC single cells under severe current cycles. ECS Proc 2005-07:534-543. https://doi.org/10.1149/200507.0534PV

Publisher's Note Springer Nature remains neutral with regard to jurisdictional claims in published maps and institutional affiliations. 